\title{
Sea-Level Rise and Species Conservation in Bangladesh's Sundarbans Region
}

\author{
Susmita Dasgupta ${ }^{1}$, Mainul Huq ${ }^{1}$, Istiak Sobhan ${ }^{1} \&$ David Wheeler ${ }^{2}$ \\ ${ }^{1}$ Development Research Group, World Bank, Washington, DC, United States \\ ${ }^{2}$ World Resources Institute, Washington, DC, United States \\ Correspondence: Susmita Dasgupta, Development Research Group, World Bank, Washington, DC, United \\ States.
}

\author{
Received: November 17, 2017 Accepted: January 24, 2018 Online Published: February 3, 2018 \\ doi:10.5539/jms.v8n1p1 URL: https://doi.org/10.5539/jms.v8n1p1
}

\begin{abstract}
This paper develops a methodology for identifying high-priority species conservation areas in Bangladesh's Sundarbans region, an UNESCO World Heritage site, considering both species vulnerability and the likelihood of inundation by future sea-level rise (SLR). Our species vulnerability analysis develops a composite spatial vulnerability indicator based on total species counts, endangered species counts, endemicity, and four measures of extinction risk from the high-resolution range maps and conservation status assessments for 378 terrestrial vertebrate species provided by IUCN Bangladesh, IUCN International and BirdLife International.

We extend the analysis by identifying areas where protection will fail if they are inundated by SLR in this century. We project SLR by 2100 at $120 \mathrm{~cm}$, near the upper bound of the current consensus, and develop digital maps of the Sundarbans region that incorporate alternative assumptions about interim subsidence $(8 \mathrm{~cm}, 35 \mathrm{~cm})$ and deposition of alluvial sediment $(0 \mathrm{~cm}, 40 \mathrm{~cm})$. We overlay these maps with our composite species vulnerability map to produce SLR-risk-adjusted maps for priority assessment.

While it would be highly desirable to protect all species of Sundarbans, resource scarcity may necessitate focusing protection on the highest-priority areas. Our analysis indicates that the highest-priority conservation status should be assigned to Sundarbans core region that has both high species vulnerability and the lowest likelihood of inundation in this century. We also identify other critical areas in four echelons of descending priority, depending upon their likelihood of inundation by sea-level rise. We hope that our methodology will contribute to cost-effective conservation management in the Sundarbans region.
\end{abstract}

Keywords: Sundarbans, biodiversity, conservation, species vulnerability, climate change, sea-level rise

\section{Introduction}

The Sundarbans is the largest continuous mangrove forest in the world, the majority of which $(6,017$ square kilometers) lies within the boundaries of Bangladesh. The rest is in West Bengal, India. The Bangladesh part comprises $4,143 \mathrm{~km}^{2}$ of land area and $1,874 \mathrm{~km}^{2}$ of water area. The region is known for its exceptional biodiversity, which includes 528 species of vascular plants (Rahman et al., 2015), 38 mammals, 297 birds, 34 reptiles, 9 amphibians, and numerous species of insects, fish, crustaceans, invertebrates and molluscs, along with diverse phytoplankton, fungi, bacteria and zooplankton (IUCN 2015). The Bangladesh Sundarbans was declared a UNESCO World Heritage site in 1997. The area is also internationally recognized under the Ramsar Convention.

Although the Sundarbans' ecological importance and uniqueness are recognized by Bangladesh and the international community, and its conservation is an obligation under international conventions and treaties, the region is currently threatened by several natural factors and human actions. The area is still in active formation as its rivers change their course. Eastward meandering of the Ganges and Brahmaputra Rivers over time is affecting sedimentation and reducing freshwater inflows significantly. In addition, water supplies, sedimentation, and the region's topography and hydrology have all been affected by human actions such as construction of upstream dams, embankments to protect land from tides, over-exploitation of mangrove timber, urban and industrial pollution, and mangrove clearing for agriculture and aquaculture. Local human-induced losses will probably continue, and climate change is likely to aggravate the current problems. 
Climate change poses several threats to the Sundarbans, including sea-level rise, increased air and water temperature, change in the frequency and intensity of precipitation and storms, and salinization of water and soil (Alongi, 2008; Dasgupta et al., 2016). Among these threats, impacts of saltwater intrusion from the sea on surface water, soil, vegetation species and freshwater fish habitats have been researched extensively in recent years (Dasgupta et al., 2016; Dasgupta et al., 2015; SRDI, 2010; UK DEFR, 2007; IWM, 2003; Peterson \& Shireen, 2001; SRDI, 2000; Karim et al., 1990).

This paper considers the inundation impacts of sea-level rise (SLR) on the habitats of various terrestrial and amphibian vertebrate species of the Bangladesh Sundarbans. According to the latest accounting by the International Union for Conservation of Nature (IUCN), conducted in 2015, 19 birds, 11 mammals and 1 reptile in the Bangladesh Sundarbans are already regionally extinct. With a virtual certainty that SLR will continue beyond 2100 even if greenhouse gas emissions are stabilized today, further habitat loss for terrestrial and amphibian vertebrate species is imminent (Loucks et al., 2010).

Even though it is widely recognized that SLR in a changing climate poses an imminent threat to this unique landscape and its resident species; scarcity of geocoded data on terrain elevation and lack of comprehensive accounting of the species have prevented a thorough vulnerability analysis of Sundarbans to-date. As a result, concerns related to SLR have not yet been incorporated into the regional management protocols for the Sundarbans. Recent developments in species range mapping and spatial assessment of potential sea-level rise offer new opportunities for informing species conservation programs in the Sundarbans region. In this paper, we draw on recently-available range information for vertebrates to develop a high-resolution species vulnerability indicator that incorporates seven sub-indicators based on species counts, endangered species counts, endemicity, and four measures of extinction risk. We combine the composite vulnerability indicator with alternative sea-level rise scenarios to identify areas that feature both high biodiversity value and robust survival prospects as climate change continues. Conservation resources will remain scarce, and priority-setting for biodiversity protection in the Sundarbans should incorporate both the expected impacts of climate change and the spatial distributions of key species. The research reported in this paper represents a step in that direction.

The paper most immediately related to our analysis is Loucks et al. (2010). It is limited to the projected impacts of SLR on Sundarbans tigers, while our paper extends the analysis to 377 additional terrestrial and amphibian vertebrate species. Our paper is of special relevance for the Government of Bangladesh for incorporating SLR-related concerns into the regional management protocols for the Sundarbans.

\section{Method}

\subsection{Data}

Our research draws on the most recent ecological and topographical information:

- Identified amphibians, birds, mammals and reptiles: The most recent IUCN data identify 378 vertebrate species in the Sundarbans, including 9 amphibians (2\% of the total), 297 birds (79\%), 38 mammals (10\%) and 34 reptiles (9\%). Summarizing by IUCN Red List threat category, 3 species are Critically Endangered ( 2 birds, 1 reptile); 7 are Endangered (3 birds, 3 mammals (including the Bengal Tiger), 1 reptile); 13 are Vulnerable (7 birds, 2 mammals, 4 reptiles); 13 are Near Threatened (12 birds, 1 mammal) and 342 are of Least Concern. Overall, 36 species (10 percent of the total) are in one of the four threatened categories.

- Range maps: Range mapping in the Sundarbans is difficult, and the most recent (2015) update from IUCN Bangladesh includes maps for 52 species: 3 amphibians, 21 birds, 15 mammals and 13 reptiles. We have completed the full suite of range maps for 378 species by adding shapefiles from IUCN International for 50 species: 6 amphibians, 23 mammals and 21 reptiles; and from BirdLife International for 276 birds.

- Measures of extinction risk for Sundarbans vertebrates are computed using information from Mooers et al. (2008) and Isaac et al. (2007). Mooers et al. (2008) convert IUCN Red List status codes (Critically Endangered, Endangered, Vulnerable, Near Threatened and Least Concern) to extinction probabilities, while Isaac et al. (2007) combine a direct extinction risk measure with a measure of each species' isolation on a phylogenetic tree.

- Elevation data: The land elevation used for this analysis is based on the most recent digital elevation model (DEM) for the coastal zone of Bangladesh, developed in 1998. Its spatial resolution is $50 \mathrm{~m}$.

- SLR projections: Regional estimates of sea-level rise are scarce. After further work on ice sheet instability in the Antarctic and Greenland, the most recent scientific literature suggests that global SLR could reach one meter or more during this century (Gillet-Chaulet et al., 2012; Hansen et al., 2015; Hay et al., 2015; DeConto \& Pollard, 2016; Hansen \& Sato, 2011; Vermeer \& Rahmstorf, 2009; Pfeffer et al., 2008; Hansen, 2006, 2007; Rahmstorf, 2007; Overpeck et al., 2006). No published scientific estimate extends the global projection to the 
Bangladesh coastal region. After consultation with Bangladesh experts, we have adopted an estimate of $120 \mathrm{~cm}$ SLR by 2100 .

The Sundarbans is in the Ganges Delta, which is still in an active, dynamic state. Therefore, it is critical to incorporate vertical land movement (subsidence or accretion) in assessments of SLR's location-specific impacts. Experts agree that vertical land movement in the lower Delta reflects alluvial deposition (sediment loading) or aggradation, tectonic subsidence and isostatic adjustments, compaction of Holocene sediments, compaction of peat layers, surface water drainage and management. However, controversy continues about the net impacts of these factors, with consequent variation in current estimates and projections of land subsidence/accretion (Pethick, 2012; ADB, 2011; Akhter et al., 2012; Syvitski et al., 2009; Nicholls \& Goodbred, 2004; Brammer, 1996; Emery \& Aubrey, 1991). To reflect these variations, our projections for 2100 include two estimates for land subsidence $(8 \mathrm{~cm}, 35 \mathrm{~cm})$ and two for sediment deposition $(0 \mathrm{~cm}, 40 \mathrm{~cm})$.

\subsection{GIS Analysis}

We combine the range map information for amphibians, birds, mammals and reptiles with alternative SLR scenarios to identify areas that feature both high biodiversity value and robust survival prospects as climate change continues. We perform the computation in three steps:

i) Spatial accounting for species diversity and vulnerability: We overlay a grid with cell size .0025 decimal degrees (approximately 250 meters) on the Sundarbans region and count all species by class and IUCN threat category within each cell. We develop a variety of biodiversity indicators to identify concentrations of diverse species and their vulnerability to encroachment and habitat loss.

ii) A composite vulnerability indictor: We develop the indicator for vertebrate species from the sub-indicators developed in Step 1.

iii) Projected inundation: We overlay the inundation zones projected for alternative scenarios of SLR, subsidence and sediment deposition to estimate the composite vertebrate species risk.

\subsubsection{Spatial Accounting for Species Diversity and Vulnerability}

\section{Species Count}

Our first indicator is the total species count for each cell. This provides a proxy for overall biodiversity at potential risk.

\section{Species Vulnerability}

The total species count provides useful information on the spatial distribution of species for assessing ecological risks, but three other elements are needed for risk assessment:

1) Geographic vulnerability, which can be proxied by endemicity: the proportion of each species' range that lies within each cell. Species that reside in very few cells may be particularly vulnerable to habitat encroachment. Endemicity treats all species equally at the regional level, since each species has a total count of 1 . Total endemicity for each cell-the sum of its species endemicity measures - assigns higher values to cells inhabited by species whose ranges are relatively limited.

2) Presence of endangered and critically endangered species. Risk assessment is particularly critical for species listed as endangered by IUCN. Our indicator is the count of endangered and critically endangered species in each cell.

3) Extinction risk. We convert Red List status codes to extinction probabilities using the methodology of Mooers et al. (2008). For species indicator construction, we normalize these probabilities so that a weight of 1.0 is assigned to species in the highest category (Critically Endangered). Table 1 tabulates conversions from Red List codes to normalized species weights, using four probability assignments. Three columns employ IUCN estimates to derive measures of extinction probability over the next 50,100 and 500 years. The fourth draws on Isaac et al. (2007) to combine a direct extinction risk measure with a measure of each species' isolation on a phylogenetic tree. 
Table 1. Normalized species aggregation weights ${ }^{\mathrm{a}}$

\begin{tabular}{llllll}
\hline & \multicolumn{5}{c}{$\begin{array}{c}\text { Normalized Extinction Probabilities } \\
\text { IUCN: Future Years }\end{array}$} \\
\hline IUCN Code & Status & Isaac $^{\mathrm{b}}$ & 50 & 100 & 500 \\
CR & Critically Endangered & 1.00000 & 1.00000 & 1.00000 & 1.00000 \\
EN & Endangered & 0.50000 & 0.43299 & 0.66770 & 0.99600 \\
VU & Vulnerable & 0.25000 & 0.05155 & 0.10010 & 0.39000 \\
NT & Near Threatened & 0.12500 & 0.00412 & 0.01000 & 0.02000 \\
LC & Least Concern & 0.06250 & 0.00005 & 0.00010 & 0.00050 \\
& Rounded Weight Ratios & & & & \\
& CR:EN & 2 & 2 & 1 & 1 \\
& CR:VU & 4 & 19 & 10 & 3 \\
& CR:NT & 8 & 243 & 100 & 50 \\
& CR:LC & 16 & 20,000 & 10,000 & 2,000 \\
\hline
\end{tabular}

Note. ${ }^{a}$ Data source: Mooers et al. (2008). ${ }^{b}$ From calculations by Mooers et al., based on Isaac et al. (2007).

Table 1 shows that Isaac's inclusion of the phylogenetic isolation factor changes the weight ratios substantially, particularly for species in the lowest threat category (Least Concern). We explore the implications for hypothetical areas A and B in Table 2. A is populated by only 2 species, both rated as Critically Endangered. B is populated by 20,000 species, but all are rated as of Least Concern. Our extinction risk indicator for each area is the sum of normalized extinction probabilities for resident species. Assignment of weights for Mooers' IUCN-derived 50-year extinction probabilities yields a total risk indicator of 2 for A-twice the total for B, because each Critically Endangered species is weight-equivalent to 20,000 Least Concern species. In contrast, assignment of the Isaac weights yields an overall risk rating for B $(1,250)$ that is 625 times greater than the rating for A (2), because each Critically Endangered Species is weight-equivalent to 16 species of Least Concern. The other two cases are intermediate, but far closer to the 50-year IUCN case.

Table 2. Implications of alternative weighting schemes

\begin{tabular}{|c|c|c|c|c|c|c|}
\hline \multirow[b]{2}{*}{ Area } & \multirow[b]{2}{*}{ Species Count } & \multirow[b]{2}{*}{$\begin{array}{c}\text { Status (Uniform Within } \\
\text { Areas) }\end{array}$} & \multicolumn{4}{|c|}{$\begin{array}{c}\text { Total Scores } \\
\text { IUCN Extinction Probabilities: } \\
\text { Future Years } \\
\end{array}$} \\
\hline & & & Isaac & 50 & 100 & 500 \\
\hline A & 2 & $\mathrm{CR}$ & 2 & 2 & 2 & 2 \\
\hline $\mathrm{B}$ & 20,000 & $\mathrm{LC}$ & 1,250 & 1 & 2 & 10 \\
\hline
\end{tabular}

To incorporate the diversity of approaches to measuring species' vulnerability, we develop seven spatial indicators: total species count; the count for Critically Endangered and Endangered species; endemicity; and four measures of species extinction risk (Isaac and $\operatorname{IUCN}(50,100,500)$ ).

\subsubsection{Computation of a Composite Vulnerability Indicator}

In principle, we could construct a composite indicator from a linear weighted combination of the seven indicators. Given the potentially-large differences illustrated by Table 2, however, it is important to know whether different weighting schemes could produce significantly different results. Table 3 reports rank correlations for the seven indicators across the 255,228 grid cells in our database. We use rank correlations to prevent relatively few large numbers in the highest-ranking cells from dominating the results. 
Table 3. Rank correlation coefficients for species distribution measures

\begin{tabular}{|c|c|c|c|c|c|c|c|}
\hline & & $\begin{array}{c}\text { Total } \\
\text { Species Count }\end{array}$ & $\begin{array}{c}\text { Endangered } \\
\text { Species Count }\end{array}$ & Endemicity & Isaac & $\begin{array}{c}\text { IUCN } \\
50 \\
\end{array}$ & $\begin{array}{c}\text { IUCN } \\
100 \\
\end{array}$ \\
\hline \multirow{6}{*}{$\begin{array}{l}\text { Extinction } \\
\text { Risk }\end{array}$} & Endangered & 0.7137 & & & & & \\
\hline & Endemicity & 0.4304 & 0.5502 & & & & \\
\hline & Isaac & 0.8841 & 0.8817 & 0.5766 & & & \\
\hline & IUCN 50 & 0.7102 & 0.9088 & 0.6354 & 0.9131 & & \\
\hline & IUCN 100 & 0.7307 & 0.9214 & 0.6304 & 0.9284 & 0.9970 & \\
\hline & IUCN 500 & 0.7891 & 0.9194 & 0.5941 & 0.9436 & 0.9650 & 0.9780 \\
\hline
\end{tabular}

We find a varied pattern, with correlations between total species count and the other indicators ranging from .43 to 0.88 . Correlations between the Isaac and IUCN measures are all high, ranging from 0.91 to 0.99 . The low correlations for endemicity are particularly striking: 0.43 for total species count, .55 for endangered species count, and from 0.58 to 0.64 for the Isaac and IUCN extinction risk measures. Overall, the results suggest that a composite linear-weighted indicator may be sensitive to the choice of component weights.

With such notable differences in correlations, it is difficult to defend the use of any particular linear weighted combination of sub-indicators because we have no a priori basis for selecting a weighting scheme. On the other hand, priority-setting is greatly facilitated by the use of a composite indicator. To accommodate diverse concerns, we adopt a conservative strategy for indicator construction. We compute ranks for all seven indicators and normalize to the range $0-100$. Then, for each $250 \mathrm{~m}$ cell, we select the maximum indicator value as our vulnerability measure. This ensures that the composite indicator will identify areas that have high vulnerability scores for any sub-indicator.

\subsubsection{Projected Inundation}

We consider the potential impact of $120 \mathrm{~cm}$ SLR by 2100 , modified by two estimates of potential land subsidence $(8 \mathrm{~cm}, 35 \mathrm{~cm})$ and two projections of sediment deposition $(0 \mathrm{~cm}, 40 \mathrm{~cm})$. To identify potential ecological impacts, we overlay the corresponding maps on our map of the vertebrate species composite vulnerability indicator.

\section{Results}

\subsection{Species Accounting for the Sundarbans Region}

Figure 1 displays three of our spatial indicators for vertebrate species in the Bangladesh Sundarbans: total species count, endangered species count, and endemicity. To facilitate comparisons, we normalize all results to percentiles (maximum value $100 \%$ ) and color as follows: red $(80-100 \%)$; dark orange $(60-80 \%)$; orange (40-60\%); light orange (20-40\%); pale yellow (0-20\%). The core Sundarbans region lies within the grey outline on each map. The three indicators all reflect important components of diversity but, as Figure 1 shows, their overall spatial distributions are far from identical. One common element is clear and highly significant for this exercise: The core Sundarbans region dominates the $80-100 \%$ percentile measures in each case. Elsewhere, however, the distributions are strikingly different. To illustrate: Outside the core Sundarbans, the higher percentiles (red and dark orange) are concentrated in the eastern area for total species count; divided into roughly-equivalent western and eastern concentrations for endangered species count; and divided into concentrations in the far west, far east and nearer the center for species endemicity. 


\section{Total species count}

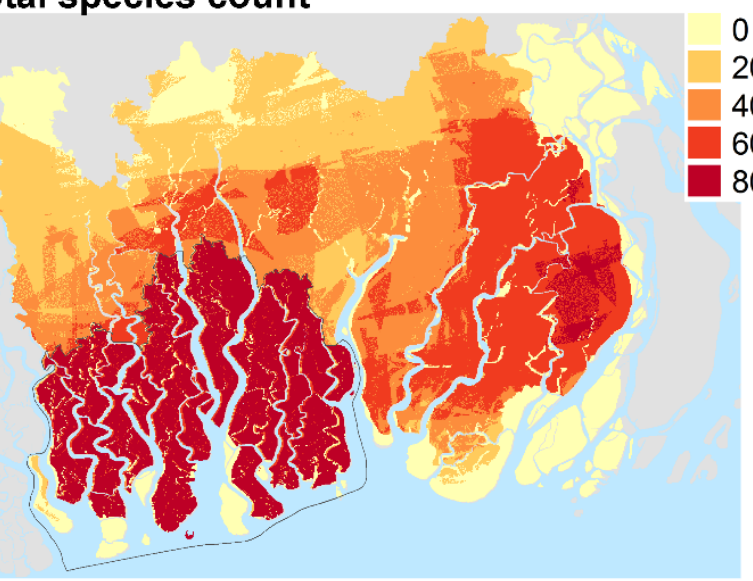

\section{Endangered species count}
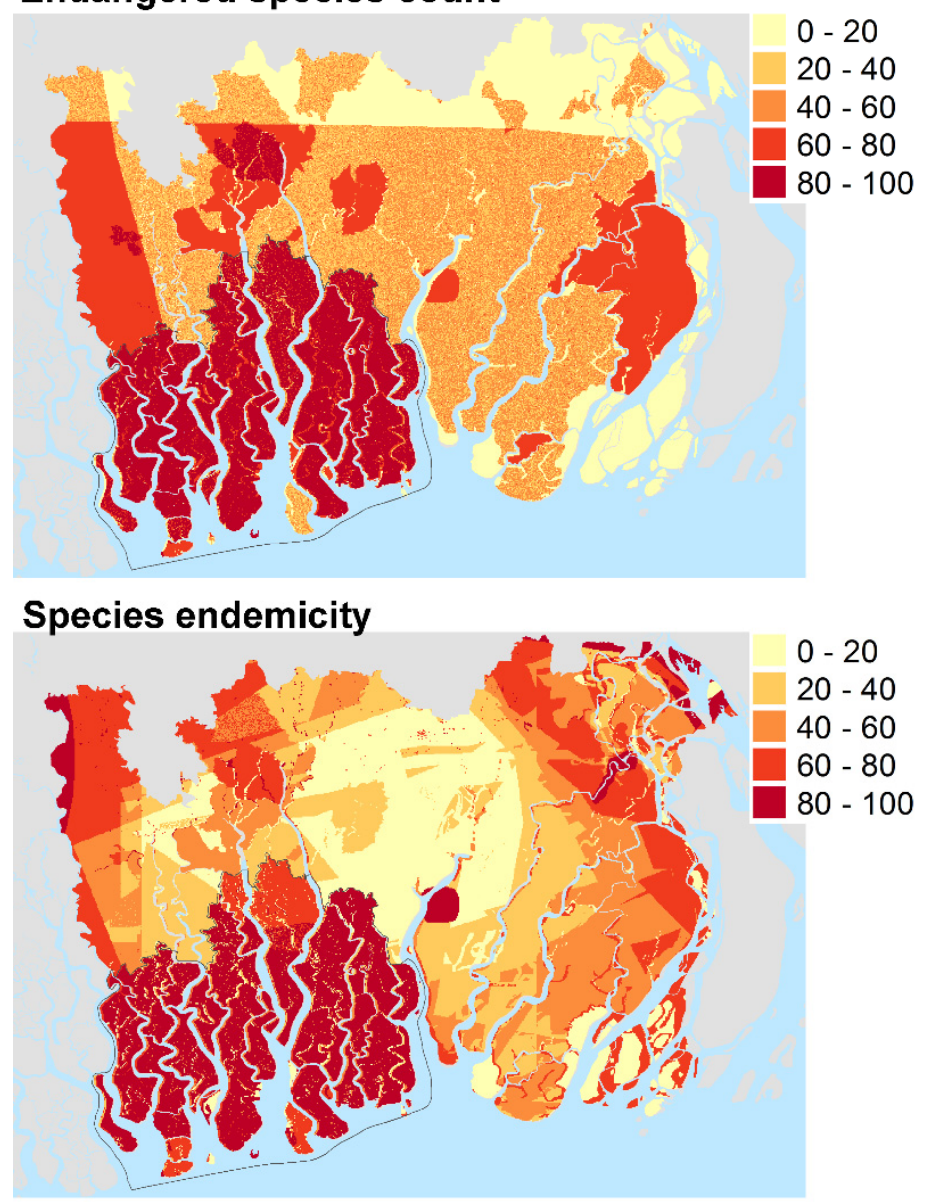

Figure 1. Sundarbans region

\subsection{Composite Vulnerability Indicator}

Figure 2 displays the geographic distribution of composite indicator values. Visual comparison with Figure 1 highlights two salient features. First, as intended, high-ranking areas in each figure reappear in Figure 2. Second, as a natural consequence of our conservative selection criterion, typical cell values are higher in Figure 2 . The highest-value (red, dark orange) areas in Figure 1 can be interpreted as having at least one high-percentile indicator value, while the lowest (pale yellow, light orange) areas can be interpreted as having low indicator values in all cases. 


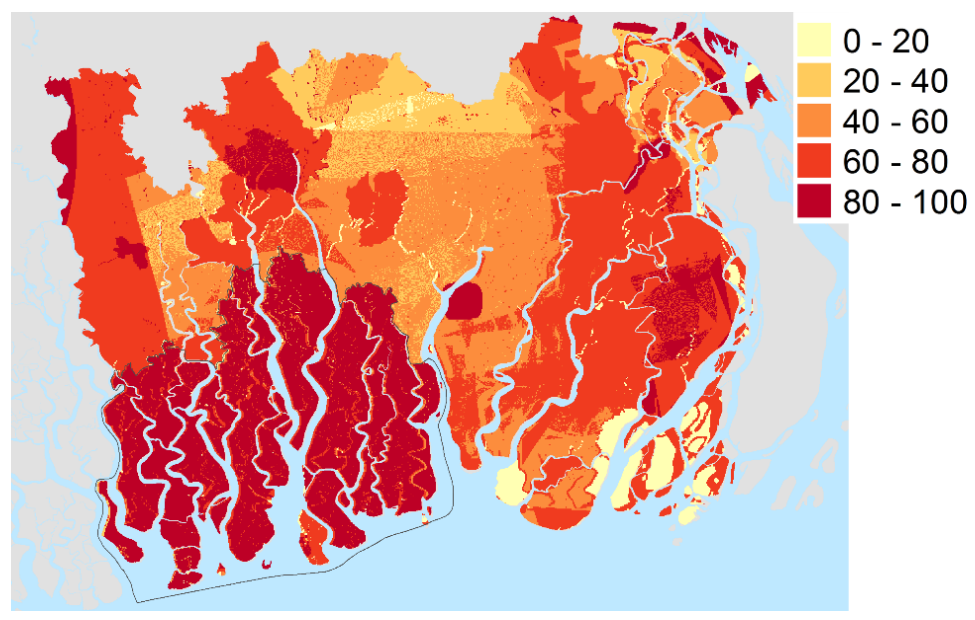

Figure 2. Sundarbans region: composite indicator value

To summarize, Figure 2 highlights species vulnerability (red) in the Sundarbans core region (within the grey boundary line) and smaller areas in the northwest and east-central regions. In addition, large areas in the northwest and east have relatively high (dark orange) vulnerability. In contrast, relatively small areas in the southeast and north-central areas have exceptionally low vulnerability. These may be important for the selection of priority conservation areas, since some areas of high species vulnerability may be inundated by future SLR while others may remain above water for the remainder of this century.

\subsection{Accounting for Future Sea-Level Rise}

a. SLR $120 \mathrm{~cm}$; subsidence $8 \mathrm{~cm}$; deposition $40 \mathrm{~cm}$

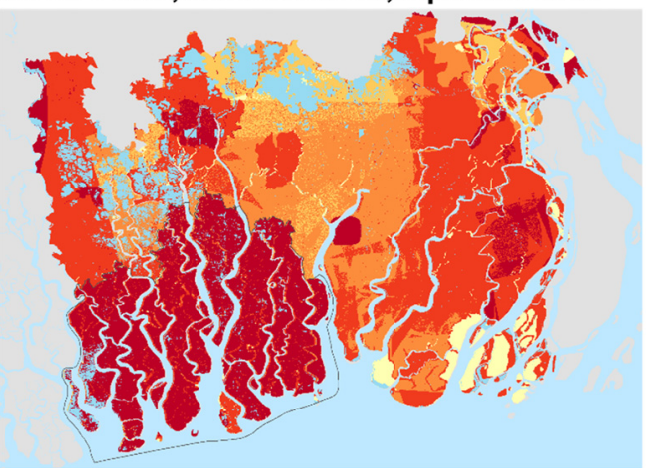

c. SLR $120 \mathrm{~cm}$; subsidence $8 \mathrm{~cm}$; deposition $0 \mathrm{~cm}$

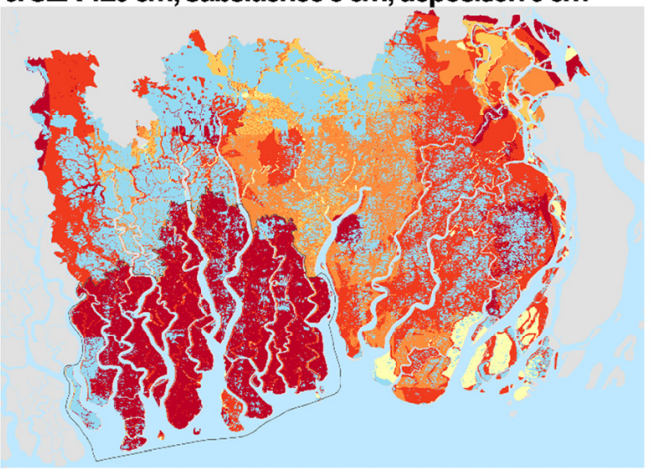

Percent

$0-20$ b. SLR $120 \mathrm{~cm}$; subsidence $35 \mathrm{~cm}$; deposition $40 \mathrm{~cm}$

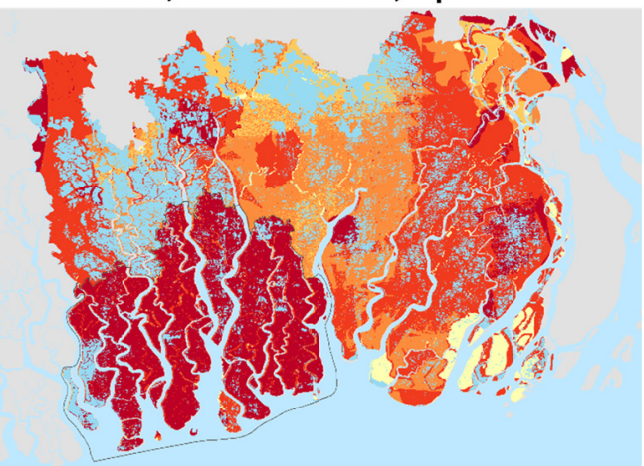

d. SLR $120 \mathrm{~cm}$; subsidence $35 \mathrm{~cm}$; deposition $0 \mathrm{~cm}$

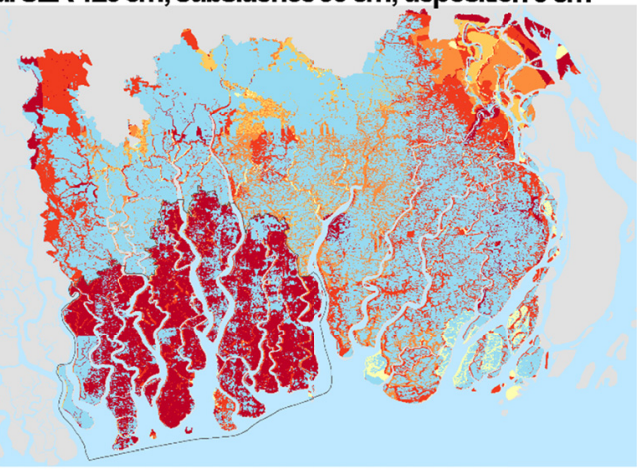

$80-100$

Figure 3. Sundarbans region: SLR-risk adjusted maps of composite indicator of species vulnerability 
Figure 3 provides sequential projections of inundation (in blue), from the lowest-impact case (subsidence $8 \mathrm{~cm}$, deposition $40 \mathrm{~cm}$ ) to the highest (subsidence $35 \mathrm{~cm}$, deposition $0 \mathrm{~cm}$ ). Figure $3 \mathrm{a}$ indicates that the lowest-impact case will only threaten a few high-vulnerability areas. Projected inundation zones are largely in the northwest and north, with some coverage of red and dark orange areas. Such areas (along with a few smaller areas in the east) are least likely to remain above water in this century, since inundation is projected to occur even under the most optimistic assumptions about subsidence and deposition.

Figure $3 \mathrm{~b}$ retains a deposition of $40 \mathrm{~cm}$ but increases projected subsidence to $35 \mathrm{~cm}$. Projected inundation areas expand substantially in the northwest and north, and many high-vulnerability areas in the east are also inundated in this scenario. The impact is compounded in the next-worst scenario, Figure $3 \mathrm{c}$, with notable expansion of inundation in high-vulnerability eastern areas. Finally, Figure 3d projects the worst case: land subsidence of 35 $\mathrm{cm}$, coupled with alluvial soil deposition of $0 \mathrm{~cm}$. In this scenario, most of the region outside the core Sundarbans is effectively inundated, except for some high-vulnerability areas in the northwest and northeast. This scenario also inundates significant parts of the Sundarbans core region, although much of that area remains above water.

\section{Discussion}

This study develops an ecological risk assessment for the Bangladesh Sundarbans based on two major components: vulnerability indicators for 378 resident vertebrate species, and potential inundation from sea-level rise, mitigated or aggravated by land subsidence and alluvial soil deposition. The results provide useful insights for the designation of conservation priority areas.

To start with, our approach incorporates three critical determinants of species vulnerability: representation, endemicity and extinction risk. We also construct indices that reflect different assumptions about time scale and phylogenetic representation. However, comparative mapping and correlation analysis show that no single indicator can serve as an adequate proxy for the set, so we build a composite indicator in three steps: (1) for each grid cell, we calculate indicator values for species count, endangered species count, endemicity and four extinction risk measures; (2) we rank the values for each indicator and normalize to percentiles in the range $0-100$; (3) we select the maximum percentile value for each grid cell. This exercise provides conservative guidance by ensuring that each grid cell is evaluated at its maximum value for the seven vulnerability indicators.

In Figure 2, without inundation, the highest-quintile (red) values of the composite indicator identify the areas that have highest priority for conservation management because they have the highest composite species vulnerability. However, addition of the SLR scenarios in Figure 3 changes the priority-setting calculus by identifying areas that have both high species vulnerability and a high likelihood of escaping inundation as SLR continues. We project SLR by 2100 at $120 \mathrm{~cm}$, near the upper bound of the current consensus, and develop four digital maps of the Sundarbans region that incorporate alternative assumptions about interim subsidence $(8 \mathrm{~cm}$, $35 \mathrm{~cm})$ and deposition of alluvial soil $(0 \mathrm{~cm}, 40 \mathrm{~cm})$. We overlay these maps with our composite species vulnerability map to produce SLR-risk-adjusted maps for priority assessment. Resulting highest-priority areas are identified by Figure $3 \mathrm{~d}$ as red and dark orange zones that remain above water in 2100, even with worst-case assumptions about subsidence and deposition. Figure $3 \mathrm{c}$ permits the identification of priority areas in the next echelon, which will be inundated in the worst-case scenario (Figure 3d) but not in the next-worst scenario [subsidence $8 \mathrm{~cm}$, deposition $0 \mathrm{~cm}$ ]. Similarly, Figure $3 \mathrm{~b}$ and Figure $3 \mathrm{a}$ can be used to identify the third and fourth priority echelons.

Thus, our methodology assigns conservation priorities to grid cells using expected conservation benefits: differential species vulnerability adjusted for the likelihood of inundation by continuing sea-level rise. Our analysis indicates that the highest-priority conservation status should be assigned to a large area in the Sundarbans core region that has both high species vulnerability and the lowest likelihood of inundation in this century. We also identify a number of smaller priority areas in the first, second, third and fourth echelons. Of course, it would be highly desirable to promote effective conservation in all of these areas. However, resource scarcity may require focusing protection on the highest-priority areas. In that case, we hope that our methodology will contribute to cost-effective conservation management in the Sundarbans region.

We acknowledge two limitations of our analysis. First, we do not incorporate existing spatial variations in habitat fragmentation because the requisite data are not available. Undoubtedly, many Sundarbans species are exposed to significant risks from the ongoing division of large, contiguous forest tracts into smaller areas, as well as edge effects. We also do not incorporate potential future fragmentation from sea-level rise. Figure $3 \mathrm{~d}$ illustrates an extreme case, which may push some resident species toward extinction. Second, the accuracy of our SLR estimates is determined by the precision of our digital elevation data. We use the best available information: the 
national DEM constructed from the FINNMAP survey data. However, the survey was conducted in 1998 and some areas of the Bengal delta may have been altered by subsequent subsidence and/or soil deposition. As Loucks et al. (2010) note, every centimeter counts in the low-lying Sundarbans and an accurate, frequently-updated DEM for the coastal region is essential for conservation planning.

Despite these limitations, we believe that our assessment of species vulnerability and potential inundation yields a relatively clear conclusion about the highest-priority areas for conservation management: the extensive parts of the Sundarbans core region that have both top-quintile species vulnerability by all of our measures (see Figures 1-2) and a very high likelihood of remaining above water, even under very pessimistic assumptions about sea-level rise, subsidence and deposition. We should also note that projected habitat losses for terrestrial species have a theoretical counterpoint in potential habitat gains for some aquatic species. However, attempting to quantify their potential significance is beyond the scope of this study.

\section{Acknowledgement}

This research is funded by the South Asia Water Initiative- Sunadrbans Targeted Environmental Studies Trust Fund administered by the World Bank. We are thankful to Ishtiaq Uddin Ahmad and Md. Shahad Mahabub. Chowdhury, IUCN- Bangladesh for providing us with data on the species of Sundarbans and their threat status. We would also like to extend our special thanks to Zahirul Huque Khan for his advice on land subsidence, sediment deposition and the tidal range of Sundarbans, Siobhan Murray for her invaluable assistance with spatial analysis, and Polly Means for her help with the graphics.

The findings, interpretations, and conclusions expressed in this paper are entirely those of the authors. They do not necessarily represent the views of the International Bank for Reconstruction and Development/World Bank and its affiliated organizations, or those of the Executive Directors of the World Bank or the governments they represent.

\section{References}

ADB (Asian Development Bank). (2011). Adapting to Climate Change: Strengthening the Climate Resilience of Water Sector Infrastructure in Khulna, Bangladesh. Retrieved from http://www.adb.org/sites/default/files/pub/2011/adapting-climate-change-ban.pdf

Akhter, S., Hasan, M., \& Khan, Z. H. (2012). Impact of Climate Change on Saltwater Intrusion in the Coastal Area of Bangladesh. Paper presented at the Eighth International Conference on Coastal and Port Engineering in Developing Countries, IIT Madras Chennai, February 20-24.

Barlow, A., Smith, J. L. D., Ahamad, I. U., \& Hossain, A. N. M. (2011). Female Tiger Panthera Tigris Home Range Size in the Bangladesh Sundarbans: The Value of This Mangrove Ecosystem for the Species' Conservation. Oryx, 45(1), 125-128. https://doi.org/10.1017/S0030605310001456

Brammer, H. (1996). Geography of Soils of Bangladesh. Dhaka, Bangladesh: University Press Ltd.

Damania, R., \& Wheeler, D. (2015). Road Improvement and Deforestation in the Congo Basin Countries. World Bank Policy Research Working Paper No. 7274.

Dasgupta, S., Huq, M., Mustafa, M. G., Sobhan, I., \& Wheeler, D. (2016). The Impact of Climate Change and Aquatic Salinization on Fish Species and Poor Communities in the Bangladesh Sundarbans. Ecological Economics, 139, 128-139. https://doi.org/10.1016/j.ecolecon.2017.04.009

Dasgupta, S., Sobhan, I., \& Wheeler, D. (2017). The Impact of Climate Change and Aquatic Salinization on Mangrove Species in the Bangladesh Sundarbans. Ambio, 46(6), 680-694.

Dasgupta, S., \& Wheeler, D. (2016). Minimizing Ecological Damage from Road Improvement Tropical Forests. World Bank Policy Research Working Paper WPS 7826. https://doi.org/10.1596/1813-9450-7826

Dasgupta, S., Kamal, F. A., Khan, Z. H., Choudhury, S., \& Nishat, A. (2015). River Salinity and Climate Change: Evidence from Coastal Bangladesh. In J. Whalley, \& J. Pan (Eds.), Asia and the World Economy-Actions on Climate Change by Asian Countries (pp. 205-242). Singapore: World Scientific Press. https://doi.org/10.1142/9789814578622_0031

Dasgupta, S., Hossain, M. M., Huq, M., \& Wheeler, D. (2015). Climate Change and Soil Salinity: The Case of Coastal Bangladesh. Ambio, 44(8), 815-826.

Dasgupta, S., \& Meisner, C. (2009). Climate Change and Sea-level rise: A Review of the Scientific Evidence. World Bank Environment Department, Paper No. 118.

DeConto, R. M., \& Pollard, D. (2016). Contribution of Antarctica to past and future sea-level rise. Nature, 531, 
591-597. https://doi.org/10.1038/nature17145

Gain, A. K., Uddin, M. N., \& Sana, P. (2008). Impact of River Salinity on Fish Diversity in the South-West Coastal Region of Bangladesh. International Journal of Ecology and Environmental Sciences, 34(1), 49-54.

Gillet-Chaulet, F., Gagliardini, O., Seddik, H., Nodet, M., Durand, G., Ritz, C., ... Greve, R. (2012). Greenland ice sheetcontribution to sea-level rise from a new-generation ice-sheet model. The Cryosphere, 6, 1561-1576. https://doi.org/10.5194/tc-6-1561-2012

Hansen, J., Sato, M., Hearty, P., Ruedy, R., Kelley, M., Masson-Delmotte, V., ... Lo, K. W. (2016). Ice melt, sea level rise and superstorms: evidence from paleoclimate data, climate modeling, and modern observations that $2{ }^{\circ} \mathrm{C}$ global warming could be dangerous. Atmospheric Chemistry and Physics, 16, 3761-3812. https://doi.org/10.5194/acp-16-3761-2016

Hansen, J. E., \& Sato, M. (2012). Paleoclimate Implications for Human-Made Climate Change. In A. Berger, F. Mesinger, \& D. Sijacki (Eds.), Climate Change. Vienna: Springer. https://doi.org/10.1007/978-3-7091-0973-1_2

Hansen, J. (2007). Scientific reticence and sea level rise. Environmental Research Letters, 2(2). https://doi.org/10.1088/1748-9326/2/2/024002

Hansen, J. (2006). Can we still avoid dangerous human-made climate change? Paper presented on December 6, 2005to the American Geophysical Union in San Francisco, California. Retrieved from http://www.columbia.edu/ jeh1/newschool_text_and_slides.pdf

Hay, C. C. et al. (2015). Probabilistic reanalysis of twentieth-century sea-level rise. Nature, 517, 481-484. https://doi.org/10.1038/nature14093

Isaac, N., Turvey, S., Collen, B., Waterman, C., \& Baillie, J. (2007). Mammals on the EDGE: conservation priorities based on threat and phylogeny. PLoS One, 2(3), e296. https://doi.org/10.1371/journal.pone.0000296

IWM (Institute of Water Modelling). (2003). Sundarban Biodiversity Conservation Project: Surface Water Modeling, Final Report. Dhaka, Bangladesh: Institute of Water Modeling, Ministry of Environment and Forests, Government of Bangladesh.

Karim, Z., Hussain, S. G., \& Ahmed, M. (1990). Salinity problems and crop intensification in the coastal regions of Bangladesh. Soils publication No. 33. Bangladesh Agricultural Research Council.

Laurance, W. F., Laurance, S. G., Ferreira, L. V., Merona, J. M. R., Gascon, C., \& Lovejoy, T. E.(1997). Biomass collapse in Amazonian forest fragments. Science, 278, 1117-1118. https://doi.org/10.1126/science.278.5340.1117

Lenore, F. (2003). Effects of habitat fragmentation on biodiversity. Annual Reviewof Ecology Evolution and Systematics, 34, 487-515. https://doi.org/10.1146/annurev.ecolsys.34.011802.132419

Loucks, C., Barber-Meyer, S., Hossain, M. A. A., Barlow, A., \& Chowdhury, R. M. (2010). Sea level rise and tigers: predicted impacts to Bangladesh's Sundarbans mangroves. Climatic Change, 98(1), 291-298. https://doi.org/10.1007/s10584-009-9761-5

Mooers, A., Faith, D., \& Maddison, W. (2008). Converting Endangered Species Categories to Probabilities of Extinction for Phylogenetic Conservation Prioritization. PLoS One, 3(11), e3700. https://doi.org/10.1371/journal.pone. 0003700

Nicholls, R. J., \& Goodbred, S. L. (2004). Towards Integrated Assessment of the Ganges-Brahmaputra Delta. Paper for Proceedings of the 5th International Conference on Asian Marine Geology and 1st Annual Meeting of IGCP475 Delta MAP and APN Mega-Deltas.

Overpeck, J., Otto-Bliesner, B., Miller, G., Muhs, D., Alley, R., \& Kiehl, J. (2006). Paleoclimatic Evidence for Future Ice-Sheet Instability and Rapid Sea-Level Rise. Science, 311, 1747-1750. https://doi.org/10.1126/science.1115159

Pethick, J. (2012). Assessing Changes in the Landform and Geomorphology Due to Sea-Level Rise in the Bangladesh Sundarbans. Report to the World Bank. Mimeo.

Petersen, L., \& Shireen, S. (2001). Soil and water salinity in the coastal area of Bangladesh. Soil Resources Development Institute, Dhaka, Bangladesh.

Pfeffer, W. T., Harper, J. T., \& O’Neel, S. (2008). Kinematic constraints on glacier contributions to 21st-century 
sea-level rise. Science, 321, 1340-1343. https://doi.org/10.1126/science.1159099

Rahman, M. S., Gazi, M. H., Khan, S. A., \& Sarder, N. U. (2015). An annotated Checklist of the Vascular Plants of Sundarban Mangrove Forest of Bangladesh. Bangladesh Journal of Plant Taxonomy, 22(1), 17-41. https://doi.org/10.3329/bjpt.v22i1.23862

Robin, L. W., Ian, G. C., David, C., Christophe, B., Simon, F. S., Ashley, H., \& Lorenzen, K. (2010). Inland capture fisheries.Philosophical Transactions of the Royal Society B, 365, 2881-2896. https://doi.org/10.1098/rstb.2010.0168

Shortridge, A., \& Messina, J. (2011). Spatial Structure and landscape association of SRTM error. Remote Sensing of Environment, 115(6), 1576-1587. https://doi.org/10.1016/j.rse.2011.02.017

Rahmstorf, S. (2007). A semi-empirical approach to projecting future sea-level rise. Science, 315, 368-370. https://doi.org/10.1126/science.1135456

SRDI. (2000). Soil salinity in Bangladesh 2000. Soil Resources Development Institute, Dhaka, Bangladesh.

SRDI. (2010). Saline Soils of Bangladesh. Soil Resources Development Institute, Dhaka, Bangladesh.

Syvitski, J. P. M., Kettner, A. J., Overeem, I., Hutton, E. W. H., Hannon, M. T., Brakenridge, G. R., ... Nicholls, R. J. (2009). Sinking Deltas Due to Human Activities. Nature Geoscience, 2, 681-686. https://doi.org/10.1038/ngeo629

UK DEFR (U.K. Department of Environment, Food and Rural Affairs). (2007). Investigating the Impact of Relative Sea-Level Rise on Coastal Communities and Their Livelihoods in Bangladesh. Dhaka, Bangladesh: Institute of Water Modellingand Center for Environment and Geographic Information Services.

Vermeer, M., \& Rahmstorf, S. (2009). Global Sea Level Linked to Global Temperature. Proceedings of the National Academy of Sciences of the United States of America, 106(51), 21527-21532. https://doi.org/10.1073/pnas.0907765106

Zheng, D., \& Chen, J. (2000). Edge effects in fragmented landscapes: a generic model for delineating area of $\begin{array}{llll}\text { edge influences (D-AEI). Ecological Modelling, } & \text { 132(3), }\end{array}$ https://doi.org/10.1016/S0304-3800(00)00254-4

Notes.

Note 1. The Sundarbans was declared a reserve forest in 1875 before the partition of India and UNESCO declared the Indian portion of the forest a World Heritage Site in 1987.

Note 2. The Sundarbans is a hostile environment for data collection and other activities. An example is provided by the risks for honey collectors, who are allowed to go inside the forest for three months a year. The available data indicate that thousands have been killed by tigers, crocodiles and snakes since human habitation of the Sundarbans began.

Note 3. A phylogenetic tree is a branching tree diagram that traces the evolutionary descent of different species from a common ancestor. Species in sparse (isolated) branches of a phylogenetic tree are relatively unique, since they share common descent patterns with fewer other species.

Note 4. The DEM, produced by the Bangladesh Inland Water Authority in 1999, is based on a map compiled from aerial photographs taken in 1990 by FINNMAP, a Finnish consulting firm, and updated using aerial photographs taken by FM-International Oy FINNMAP in 1998.

Note 5. Bangladesh is exceptionally vulnerable to sea-level rise, since it has an extremely low-lying and flat topography (Dasgupta et al., 2009). As a result, experts in Bangladesh have expressed a risk-averse preference for the $120 \mathrm{~cm}$ SLR projection, which is near the upper bound of the current scientific consensus for global adaptation planning.

Note 6. The Sundarbans is also subject to semi-diurnal tides that vary with several factors, including water depth and area width. The mean range for the spring tide is about 2.9 meters at Heron Point, 4.0 meters at Mongla, and 3 to 3.5 meters more generally. During the neap tide, the range is generally 1.5 to 2.5 meters.

Note 7. Our framework reflects prior work by the authors and colleagues on infrastructure improvement and biodiversity loss in Latin America, Africa and Asia (see Dasgupta \& Wheeler, 2016; Damania \& Wheeler, 2015).

Note 8. The IUCN's current classification categories are Critically Endangered, Endangered, Vulnerable, Near Threatened and Least Concern. 
Note 9. See footnote 3 for an explanation of the phylogenetic tree.

Note 10. The most commonly-employed linear combination is the mean, which assigns equal weights to all components.

Note 11. We retain the percentile label in Figure 2 for compatibility with Figure 1. However the label in Figure 2 refers to maximum percentiles across the seven component indicators, not the percentile value of the result in the distribution of maximum indicator values.

Note 12. To illustrate, Barlow et al. (2011) report that female tigers have an average home range of $14.2 \mathrm{~km}^{2}$ in Bangladesh. Population sustainability for tigers depends on prey density, which is also affected by habitat fragmentation.

https://wp.natsci.colostate.edu/findingporpoise/tigers-and-territory-the-issues-we-see-with-home-range-size-andconservation-in-these-big-cats/

Note 13. For a discussion of habitat fragmentation impacts, see Lenore (2003) and Laurance et al. (1997).

Note 14. Edge effects are changes in species populations at habitat boundaries caused by abrupt transitions in the species compositions of adjoining ecological communities (Zheng \& Chen 2000).

Note 15. To illustrate some dimensions of the tradeoff: Gain et al. (2008) reported a significant decline in fish diversity with increased salinity in the Sibsa River near Paikgacha. In 1975, fresh water fish species near Paikgacha were abundant, but in 2005 field sampling could not locate 17 fresh water species, including Labeo rohita, Catla catla, Anabas testudineus and Clarius batrachus. Many freshwater fish species have low swimming speeds, prefer local habitats, and will not survive increases in salinity (Robin et al., 2010). On the other hand, wild marine and brackish-water fish species prefer coastal ecosystems to river systems because of their feeding habits and biology; and may emerge gradually in inland water once inundation occurs.

\section{Copyrights}

Copyright for this article is retained by the author(s), with first publication rights granted to the journal.

This is an open-access article distributed under the terms and conditions of the Creative Commons Attribution license (http://creativecommons.org/licenses/by/4.0/). 